\title{
Healthcare Utilization and Prevalence of Symptoms in Women with Menopause: A Real-World Analysis
}

This article was published in the following Dove Press journal:

International Journal of Women's Health

\author{
Sarah Sharman Moser ${ }^{\prime}$ \\ Gabriel Chodick ${ }^{1,2}$ \\ Shikma Bar-On ${ }^{3}$ \\ Varda Shalev ${ }^{1,2}$ \\ 'Kahn-Sagol-Maccabi Research and \\ Innovation Institute, Maccabi Healthcare \\ Services, Tel Aviv, Israel; ${ }^{2}$ Sackler Faculty \\ of Medicine, Tel Aviv University, Tel Aviv, \\ Israel; ${ }^{3}$ Lis Maternity Hospital, Tel-Aviv \\ Medical Center, Tel-Aviv, Israel
}

\begin{abstract}
Objective: Self-reported studies estimated that as many as $50-75 \%$ of women experience symptoms during menopause; however, limited real-world clinical data are available to support this observation. The electronic databases of Maccabi Healthcare Services were used to describe the prevalence of menopause symptoms in Israel and to characterize patients with regard to socioeconomic status, comorbidities and use of healthcare services.

Methods: Females aged 45-54 years diagnosed with menopausal symptoms $(\mathrm{N}=17,046$, cumulative incidence of $8 \%$ during the study period) were identified from the Maccabi Healthcare Services electronic database and matched to female members without menopause symptoms, one-to-one on birth year and enumeration area.

Results: Symptomatic peri- and post-menopausal women, and particularly those under 52 years, were more likely to have a higher prevalence of comorbid conditions such as depression, anxiety, osteoporosis and insomnia in the year following index. Correspondingly, selective serotonin reuptake inhibitors, serotonin norepinephrine reuptake inhibitors and hypnotic drug use were significantly higher in symptomatic women as was healthcare utilization including hospitalization $(\mathrm{OR}=1.10 ; 95 \% \mathrm{CI}=1.00-1.20)$, primary care visits $(1.90 ; 1.73-2.08)$, gynecologist visits $(24.84 ; 22.36-27.59)$ and hysterectomy procedures $(2.26 ; 1.63-3.14)$.

Conclusion: Medically documented menopausal symptoms are associated with increased burden of disease (particularly among women diagnosed with menopausal symptoms prior to age 52 years), healthcare utilization and greater likelihood of undergoing hysterectomy within one year of diagnosis. This burden is expected to rise further as awareness and social acceptance of peri- and post-menopausal symptoms increase.
\end{abstract}

Keywords: menopause, peri-menopause, real-world study, healthcare utilization

Menopause, a normal process of aging, is defined as the absence of menstrual flow for 12 consecutive months. Menopause typically affects women between the ages of 40 to 58 years, with a median onset at 47.5 years and ending at a median age of 51.4 years. $^{1,2}$ It is estimated that $50-75 \%$ of peri-menopausal and post-menopausal women experience menopause symptoms during peri-menopause, menopause and into post-menopause, ${ }^{3-5}$ which can include hot flashes and night sweats (vasomotor symptoms), low self-rated health, sexual difficulties, insomnia, ${ }^{6,7}$ anxiety and depression. ${ }^{4,8}$ These symptoms can be severe and last for 10 years or more after the menopause transition. ${ }^{6}$ A systemic review indicated that whereas vasomotor systems are highly prevalent in most societies, ${ }^{9}$ geographical location and ethnicity influence the prevalence of certain symptoms. ${ }^{10}$ For example, age at menopause was lower in women from African, Latin American, Asian and Middle Eastern
Correspondence: Sarah Sharman Moser Kahn-Sagol-Maccabi Research and Innovation Institute, Maccabi Healthcare Services, 27 Hamered St,

Tel Aviv 6812509, Israel

Tel +972-37462778

Email moser_sa@mac.org.il 
countries as compared with Europe, Australia and the USA. Vasomotor symptoms were reported to be lower in Middle Eastern countries than Western countries, and European women or women with Latin American ethnicity had predominantly central nervous system symptoms such as mood changes, sleeplessness and irritability.

Age of onset of menopause is also influenced by other factors: lower socioeconomic status (SES), lower level of education and smoking were associated with earlier onset of menopause, whereas while being overweight or partaking in physical exercise was modestly associated with later onset of menopause, there was no clear association. $^{11}$

In addition to affecting quality of life, ${ }^{12,13}$ menopause symptoms have a considerable economic burden, with incremental total health expenditures of nearly 500 US\$ per case. ${ }^{14}$ In one study, ${ }^{15}$ severe vasomotor symptoms were associated with $82 \%$ higher all-cause outpatient visits and $121 \%$ higher specialized outpatient visits. Other studies have reported the extent that menopausal symptoms have interfered with productivity at work. ${ }^{13,16}$

Limited real-world data are available regarding menopause symptoms in Israel. This study describes the prevalence of menopause symptoms in Israel, characterizes women with regard to socioeconomic variables and comorbidities, and compares the use of healthcare services among women with diagnosed menopause symptoms to that of a matched control group.

\section{Methods}

\section{Data Source}

This retrospective cohort study was conducted using the computerized databases of Maccabi Healthcare Services (MHS), a nationwide healthcare insurer-provider representing a quarter of the population in Israel, with 2.3 million members. The MHS database contains longitudinal anonymized data that are automatically collected since 1993 for a stable population (with less than 1\% of members moving out each year), including laboratory results from a single central laboratory and pharmacy prescription and purchase data. MHS uses the International Classification of Diseases, Ninth Revision, Clinical Modification (ICD-9-CM) coding systems, as well as self-developed coding systems to provide more granular diagnostic information. Procedures are coded using Current Procedural Terminology (CPT) codes. This study was reviewed and approved by the Institutional
Review Board of the Assuta Medical Center in Israel (0101-17-BBL).

\section{Study Population}

In this retrospective cohort study, we identified female MHS members aged 45 to 54 with at least 2 diagnoses for general menopausal and post-menopausal disorders (primary, secondary, or tertiary ICD-9-CM codes of 627. $\mathrm{xx}$ ) in their electronic medical record between the years 2010 to 2015 with no evidence of a cancer diagnosis before index date (due to hot flashes being a side effect of some anti-cancer treatments). ${ }^{2}$ A total of 18,483 women aged 45 to 54 years were identified and of these, 1432 were excluded due to a prior cancer diagnosis (based on the MHS cancer registry which uses diagnosis data from the Israel Ministry of Health, linked to cancer medication approvals and pathology reports from MHS).

Women with a menopausal disorder (symptomatic women) were matched individually (one-to-one) to women without any menopausal disorder (reference group), on birth year and geographical area (particular MHS health center).

Index date for symptomatic women was defined as the date of the first menopause diagnosis and women in the reference group were assigned the same index date as their corresponding matched pair.

Women with less than one year of healthcare registration in MHS before or after index date were excluded.

\section{Study Variables}

Demographic and clinical data collected included age at index, SES, district, smoking, and prevalence of comorbid conditions. SES was categorized into quartiles based on the poverty index of the member's enumeration area, as defined by the 2008 National Census. ${ }^{17}$ The poverty index is based on several parameters including household income, education level, crowding, physical living conditions and car ownership. Smoking status was identified from physician notes in the database.

Comorbidities at baseline were identified using validated MHS registries (diabetes mellitus, hypertension, chronic obstructive pulmonary disease (COPD), cardiovascular disease, chronic kidney disease and osteoporosis) before index date. ${ }^{18-20}$ In addition, comorbidity was measured by the Deyo-Charlson Comorbidity $\operatorname{Index}^{21}$ and augmented using the MHS chronic disease registries. All comorbidities were measured in the 1-year pre-index period. 
Other comorbidities and outcomes included prevalence of selected comorbidities, procedures, and medications purchased, in the 1 year baseline period and 1-year postindex period. Comorbidities studied were identified using primary MHS registries or ICD-9-CM codes: major depression $(296.2 x-296.3 x$, or 311.xx), other depression (298.0x, 300.4x, or 309.0x-309.1x), anxiety (293.84, $300.0 x-300.3 x$, or 309.21), insomnia $(307.41,307.42$, $307.49,327.0 x$, or 780.52), osteoporosis (registry), vertebral column fracture (registry), and hip fracture (registry). Medication classes examined were hypnotics, selective serotonin reuptake inhibitors (SSRIs), serotoninnorepinephrine reuptake inhibitors (SNRIs), and bisphosphonates. Healthcare use included primary care physician (PCP) visits, gynecologist visits, hospitalizations and hysterectomy procedures.

\section{Statistical Analysis}

Baseline descriptive characteristics were compared using $t$-tests for continuous variables and chi-square tests for discrete variables. Conditional logistic regression was used to model the likelihood of having any use of services for the 1-year post-index period. The model was adjusted for potential confounders which were found to be significant between the patient groups $(p \leq 0.05)$, including diabetes mellitus, anxiety, insomnia, osteoporosis or depression before index, use of anti-depression medication, hypnotics or bisphosphonates, SES, smoking and PCP visit in the year before index date. Generalized linear regression modeling (GLM) with negative binomial and $\log$ link function was used to model the frequency of hospitalization, physician and gynecology visits in the index year, and the incremental number of visits among symptomatic women versus women in the reference group.

\section{Results}

A total of 17,046 women aged 45 to 54 years with two or more menopause diagnoses were identified between the years 2010 to 2015 (cumulative incidence of $8 \%$ of the total population during the study period) and successfully matched to women with no menopausal disorders. Mean age was 49.4 years (SD 2.5 years) and the women in the reference group had slightly higher SES ( $\mathrm{P}=0.018)$. Symptomatic women had a lower prevalence of smoking (12.4\% vs $14.0 \%, \mathrm{P}<0.001)$, diabetes mellitus $(3.7 \%$ vs $4.9 \%, \mathrm{P}<0.001)$, hypertension ( $15.4 \%$ vs $16.2 \%, \mathrm{P}=0.031$ ) and osteoporosis $(2.4 \%$ vs $3.4 \%, \mathrm{P}<0.001$ as compared to the women in the reference group at baseline. However, they had a higher proportion of depression $(6.1 \%$ vs $5.0 \%)$, anxiety $(6.5 \%$ vs $4.7 \%)$ and insomnia $(2.0 \%$ vs $1.3 \%$ ) (all $\mathrm{P}<0.001$ ); and anti-depression (for SSRI $8.3 \%$ vs $7.3 \%$, SNRI $2.8 \%$ vs $2.3 \%)$ and anti-anxiety $(11.7 \%$ vs 9.2\%) medication purchases (all $\mathrm{P}<0.001$ except SNRI medications $\mathrm{P}=0.002$ ), as compared to the women in the reference group in the year before index date (Tables 1 and

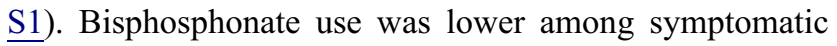
women $(0.7 \%$ vs $1.0 \%, \mathrm{P}<0.001)$.

In the baseline year, symptomatic women had a higher frequency of hospitalizations $(5.9 \%$ vs $5.3 \%, \mathrm{P}=0.02)$, PCP and gynecologist visits (at least one visit: $93.0 \%$ vs $87.9 \%$ and $57.8 \%$ vs $44.5 \%$, respectively, both $\mathrm{P}<0.001$ ); however no difference was seen in median length of stay among those hospitalized or median number of gynecology visits (Table 2). In addition a small percent of women had hysterectomy procedures prior to index date, with no difference between symptomatic and women in the reference group $(0.6 \%$ vs $0.5 \%, \mathrm{P}=0.16)$.

One-year post-index, symptomatic women were significantly more likely than women in the reference group to have a diagnosis of depression (not major depression), anxiety and osteoporosis for ages 44-52, and insomnia, across all age groups (Figure 1).

Correspondingly, SSRI, SNRI and hypnotic use were significantly higher for symptomatic women for ages 44-52 (Figure 2).

Categorical healthcare utilization (yes/no) for the oneyear post-index prevalence showed a slight difference in hospitalization, and significantly higher PCP and gynecology visits for all age groups (Figure 3), and hysterectomy procedures (Figure S1) for symptomatic women as compared to women in the reference group, with the following adjusted odds ratios $(95 \% \mathrm{CI})$ : hospitalizations 1.10 (1.01-1.21), PCP visits 1.90 (1.73-2.08), gynecologist visits 24.84 (22.36-27.59) and hysterectomy procedures 2.26 (1.63-3.14) (Table 3).

Adjusted odds ratios associated with frequency of hospitalizations, PCP visits and gynecologist visits for symptomatic women were statistically significant: hospitalizations 1.12 (1.03-1.22), PCP visits 1.15 (1.13-1.18) and gynecologist visits 2.15 (2.09-2.22), and symptomatic women had an increase in added visits per year of $1.07(0.89,1.25)$ to a PCP and $1.09(1.03,1.14)$ to a gynecologist (Table 4).

More detailed comparison of study groups is given in $\underline{\text { Tables } \mathrm{S} 2}$ and $\underline{\mathrm{S}}$. 
Table I Demographic and Clinical Characteristics of the Study Population for Matched Cohort of Symptomatic Women vs Women in the Reference Group at Index Date (Date of First Menopause Symptom). ( $N=34,092)$. All N (\%) Unless Otherwise Stated

\begin{tabular}{|c|c|c|c|}
\hline & $\begin{array}{l}\text { Reference } \\
\text { Group } \\
\text { (Controls) } \\
n=17,046\end{array}$ & $\begin{array}{l}\text { Symptomatic } \\
\text { Women } \\
\text { (Cases) } \\
n=17,046\end{array}$ & P-value \\
\hline \multicolumn{4}{|l|}{ Demographic } \\
\hline Age $y$, median (IQR) & $\begin{array}{l}49.00(47.00 \\
51.00)\end{array}$ & $\begin{array}{l}49.00(48.00 \\
51.00)\end{array}$ & 0.802 \\
\hline $\begin{array}{l}\text { District } \\
\text { Centre } \\
\text { North } \\
\text { South }\end{array}$ & $\begin{array}{l}10,808(63.4 \%) \\
3,088(18.1 \%) \\
3,150(18.5 \%)\end{array}$ & $\begin{array}{l}10,808(63.4 \%) \\
3,088(18.1 \%) \\
3,150(18.5 \%)\end{array}$ & 1.00 \\
\hline $\begin{array}{l}\text { Socioeconomic } \\
\text { status* } \\
\text { Ist (lowest) } \\
\text { 2nd } \\
\text { 3rd } \\
\text { 4th (highest) }\end{array}$ & $\begin{array}{l}5,521 \text { (32.4\%) } \\
3,422(20.1 \%) \\
3,38 \mid(19.8 \%) \\
4,722(27.7 \%)\end{array}$ & $\begin{array}{l}5,249(30.8 \%) \\
3,512(20.6 \%) \\
3,455(20.3 \%) \\
4,830(28.3 \%)\end{array}$ & 0.018 \\
\hline Clinical indices & & & \\
\hline $\begin{array}{l}\text { Smoking status } \\
\text { Never } \\
\text { Ever } \\
\text { Unknown }\end{array}$ & $\begin{array}{l}14,1 \mid 9(82.8 \%) \\
2,384(14.0 \%) \\
543(3.2 \%)\end{array}$ & $\begin{array}{l}14,552(85.4 \%) \\
2,1 \mid 8(12.4 \%) \\
376(2.2 \%)\end{array}$ & $<0.001$ \\
\hline $\begin{array}{l}\text { Deyo-Charlson } \\
\text { Index } \\
0 \\
1 \\
3 \\
\geq 4\end{array}$ & $\begin{array}{l}2,725(16.0 \%) \\
886(5.2 \%) \\
285(1.7 \%) \\
127(0.7 \%)\end{array}$ & $\begin{array}{l}2,796(16.4 \%) \\
887(5.2 \%) \\
261(1.5 \%) \\
103(0.6 \%)\end{array}$ & 0.344 \\
\hline $\begin{array}{l}\text { Comorbidities } \\
\text { Diabetes mellitus } \\
\text { Cardiovascular } \\
\text { disease } \\
\text { Hypertension } \\
\text { Chronic kidney } \\
\text { disease } \\
\text { COPD } \\
\text { Osteoporosis } \\
\text { Major depression } \\
\text { Other depression } \\
\text { Anxiety } \\
\text { Insomnia }\end{array}$ & $\begin{array}{l}831(4.9 \%) \\
613(3.6 \%) \\
2,765(16.2 \%) \\
475(2.8 \%) \\
99(0.6 \%) \\
580(3.4 \%) \\
82(0.5 \%) \\
848(5.0 \%) \\
808(4.7 \%) \\
228(1.3 \%)\end{array}$ & $\begin{array}{l}631(3.7 \%) \\
607(3.6 \%) \\
2,620(15.4 \%) \\
459(2.7 \%) \\
68(0.4 \%) \\
416(2.4 \%) \\
103(0.6 \%) \\
1,037(6.1 \%) \\
1,107(6.5 \%) \\
347(2.0 \%)\end{array}$ & $\begin{array}{l}<0.001 \\
0.861 \\
0.031 \\
0.596 \\
\\
0.016 \\
<0.001 \\
0.122 \\
<0.001 \\
<0.001 \\
<0.001\end{array}$ \\
\hline $\begin{array}{l}\text { Hysterectomy } \\
\text { I year before } \\
\text { index }\end{array}$ & $81(0.5 \%)$ & $100(0.6 \%)$ & 0.157 \\
\hline
\end{tabular}

(Continued)
Table I (Continued).

\begin{tabular}{|c|c|c|c|}
\hline & $\begin{array}{l}\text { Reference } \\
\text { Group } \\
\text { (Controls) } \\
n=17,046\end{array}$ & $\begin{array}{l}\text { Symptomatic } \\
\text { Women } \\
\text { (Cases) } \\
n=17,046\end{array}$ & P-value \\
\hline \multicolumn{4}{|l|}{$\begin{array}{l}\text { Medication use } \\
\text { within } 6 \text { months } \\
\text { before index }\end{array}$} \\
\hline $\begin{array}{l}\text { Anti-anxiety } \\
\text { (hypnotics) }\end{array}$ & I,575 (9.2\%) & 2,001 (11.7\%) & $<0.001$ \\
\hline SSRI & I,236 (7.3\%) & I,416 (8.3\%) & $<0.001$ \\
\hline SNRI & $388(2.3 \%)$ & $476(2.8 \%)$ & 0.002 \\
\hline Bisphosphonates & 177 (I.0\%) & $114(0.7 \%)$ & $<0.001$ \\
\hline
\end{tabular}

Notes: *Socioeconomic status is based on the poverty index of the member's enumeration area, as defined by the 2008 National Census. The poverty index is based on parameters including household income, educational level, crowding, physical conditions and car ownership. A higher score indicates higher level of SES.

Abbreviations: COPD, chronic obstructive pulmonary disease; SSRI, selective serotonin reuptake inhibitors; SNRI, serotonin-norepinephrine reuptake inhibitor.

Table 2 Healthcare Utilization in the I- Year Baseline Period $(\mathrm{N}=34,092)$

\begin{tabular}{|c|c|c|c|}
\hline & $\begin{array}{l}\text { Reference } \\
\text { Group } \\
\text { (Controls) } \\
n=17,046\end{array}$ & $\begin{array}{l}\text { Symptomatic } \\
\text { Women } \\
\text { (Cases) } \\
\mathrm{n}=17,046\end{array}$ & P-value \\
\hline \multicolumn{4}{|l|}{ Hospitalization } \\
\hline $\mathrm{N}(\%)$ & 902 (5.3\%) & $\mathrm{I}, 002(5.9 \%)$ & 0.018 \\
\hline Median (IQR) & $2(1,4)$ & $2(1,4)$ & 0.215 \\
\hline number of nights & & & \\
\hline in the baseline & & & \\
\hline year for those & & & \\
\hline hospitalized & & & \\
\hline Median (IQR) & $I(I, I)$ & $\mathrm{I}(\mathrm{I}, \mathrm{I})$ & 0.840 \\
\hline number of & & & \\
\hline separate & & & \\
\hline hospitalizations & & & \\
\hline I & $86.3 \%$ & $85.9 \%$ & 0.663 \\
\hline 2 & $10.0 \%$ & $10.0 \%$ & \\
\hline$\geq 3$ & $3.8 \%$ & $4.1 \%$ & \\
\hline \multicolumn{4}{|l|}{ PCP visits } \\
\hline$\geq 1$ & |4,987 (87.9\%) & 15,856 (93.0\%) & $<0.001$ \\
\hline$\geq 5$ & 9,403 (55.2\%) & $10,633(62.4 \%)$ & $<0.001$ \\
\hline Median (IQR) & $6(3,10)$ & $7(4,11)$ & $<0.001$ \\
\hline \multicolumn{4}{|l|}{$\begin{array}{l}\text { Gynecologist } \\
\text { visits }\end{array}$} \\
\hline$\geq 1$ & 7,590 (44.5\%) & 9,849 (57.8\%) & $<0.001$ \\
\hline Median (IQR) & $2(1,3)$ & $2(1,3)$ & 0.084 \\
\hline
\end{tabular}

Abbreviation: PCP, primary care physician. 


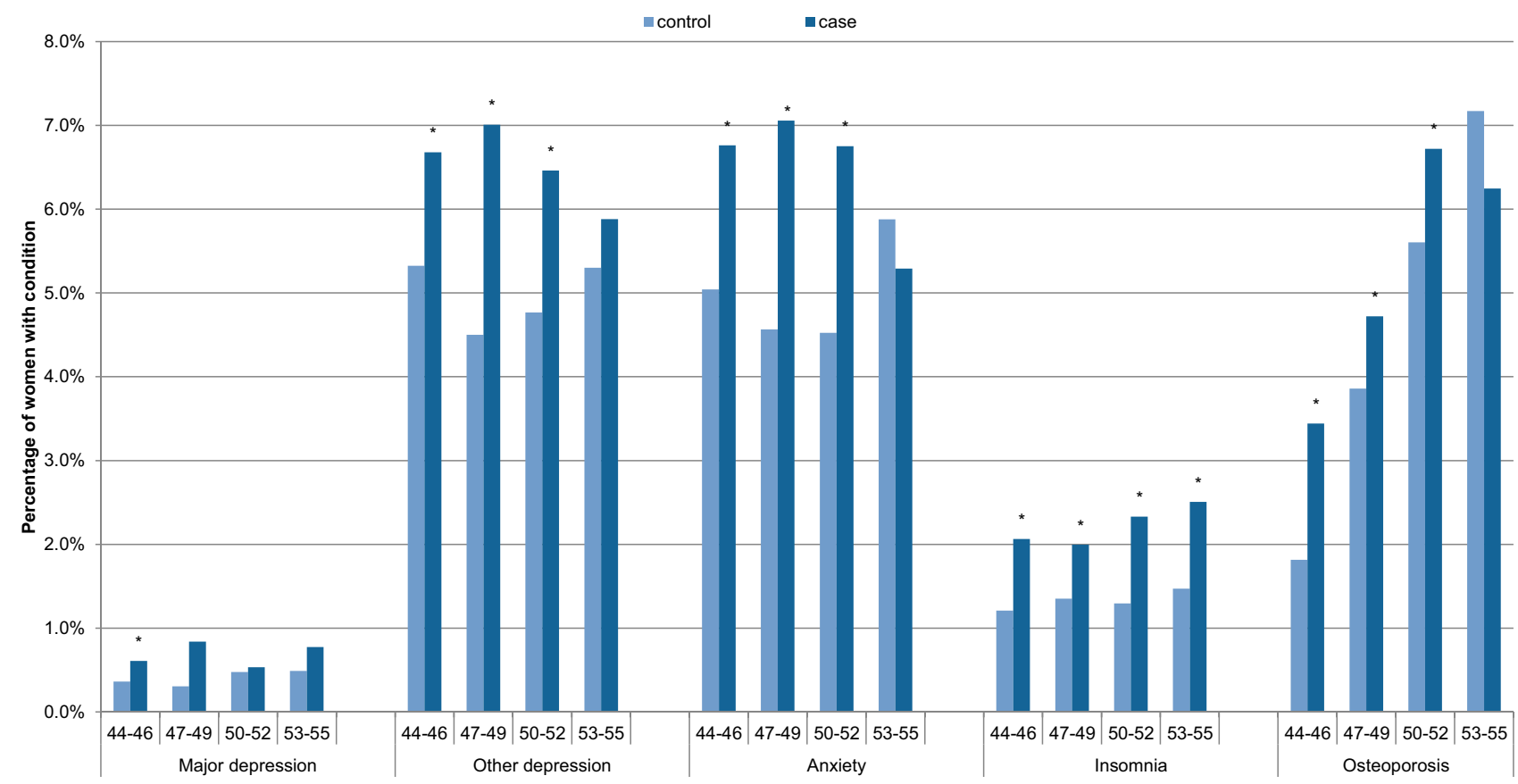

Figure I One-year post-index prevalence of comorbid conditions for symptomatic women (cases) versus women in the reference group (controls), by age, $\mathrm{N}=34,092$. *Significant difference between menopause and control cohorts.

\section{Discussion}

The results of this analysis indicate that symptomatic women are associated with an increased burden of disease and healthcare utilization including hospitalizations, PCP visits, gynecologist visits and a greater likelihood of undergoing hysterectomy in the year following diagnosis.

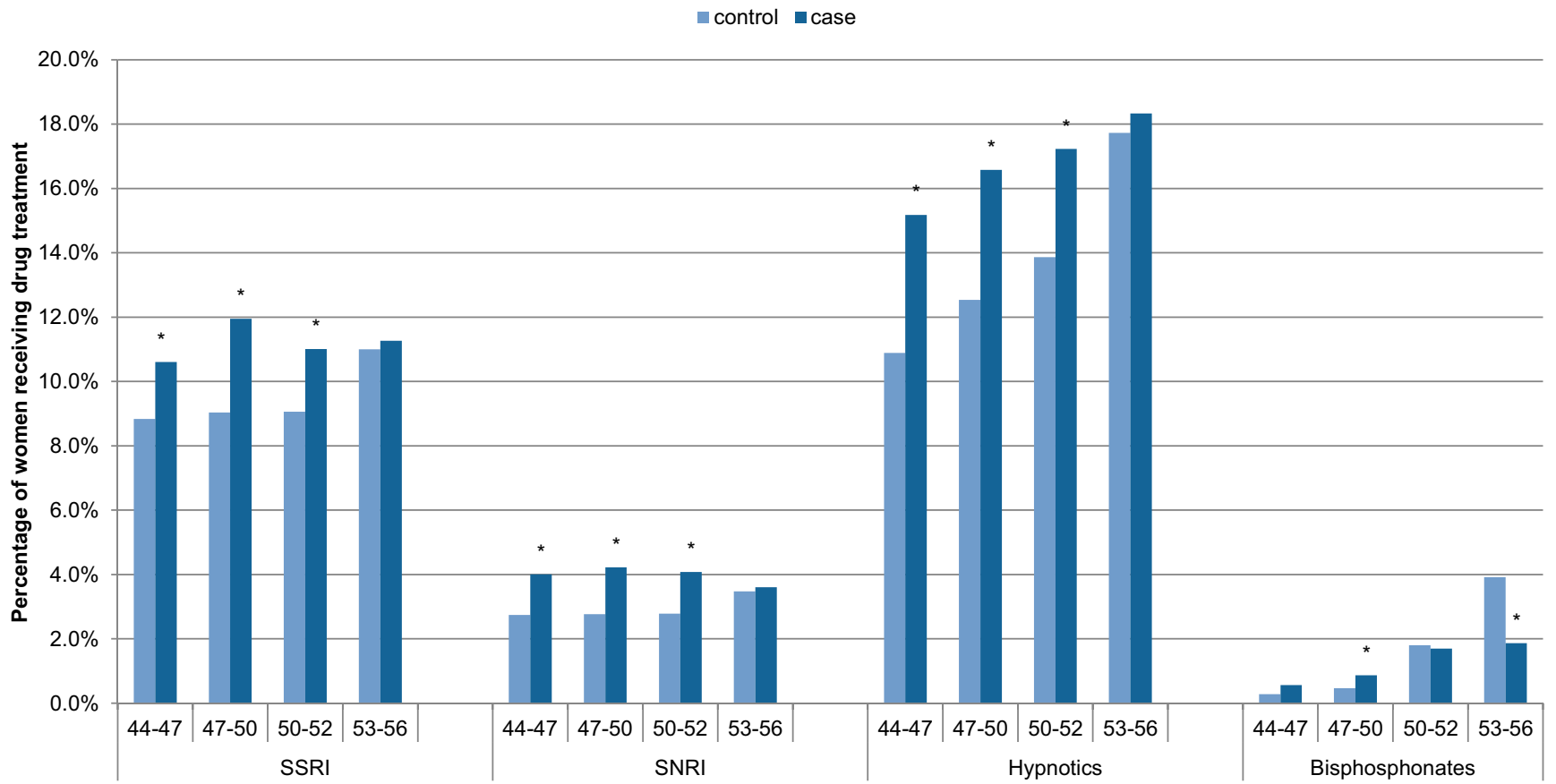

Figure 2 One-year post-index prevalence of medication for symptomatic women (cases) versus women in the reference group (controls), by age $\mathrm{N}=34,092 . *$ Significant difference between menopause and control cohorts.

Abbreviations: SSRI, selective serotonin reuptake inhibitors; SNRI, serotonin-norepinephrine reuptake inhibitor. 


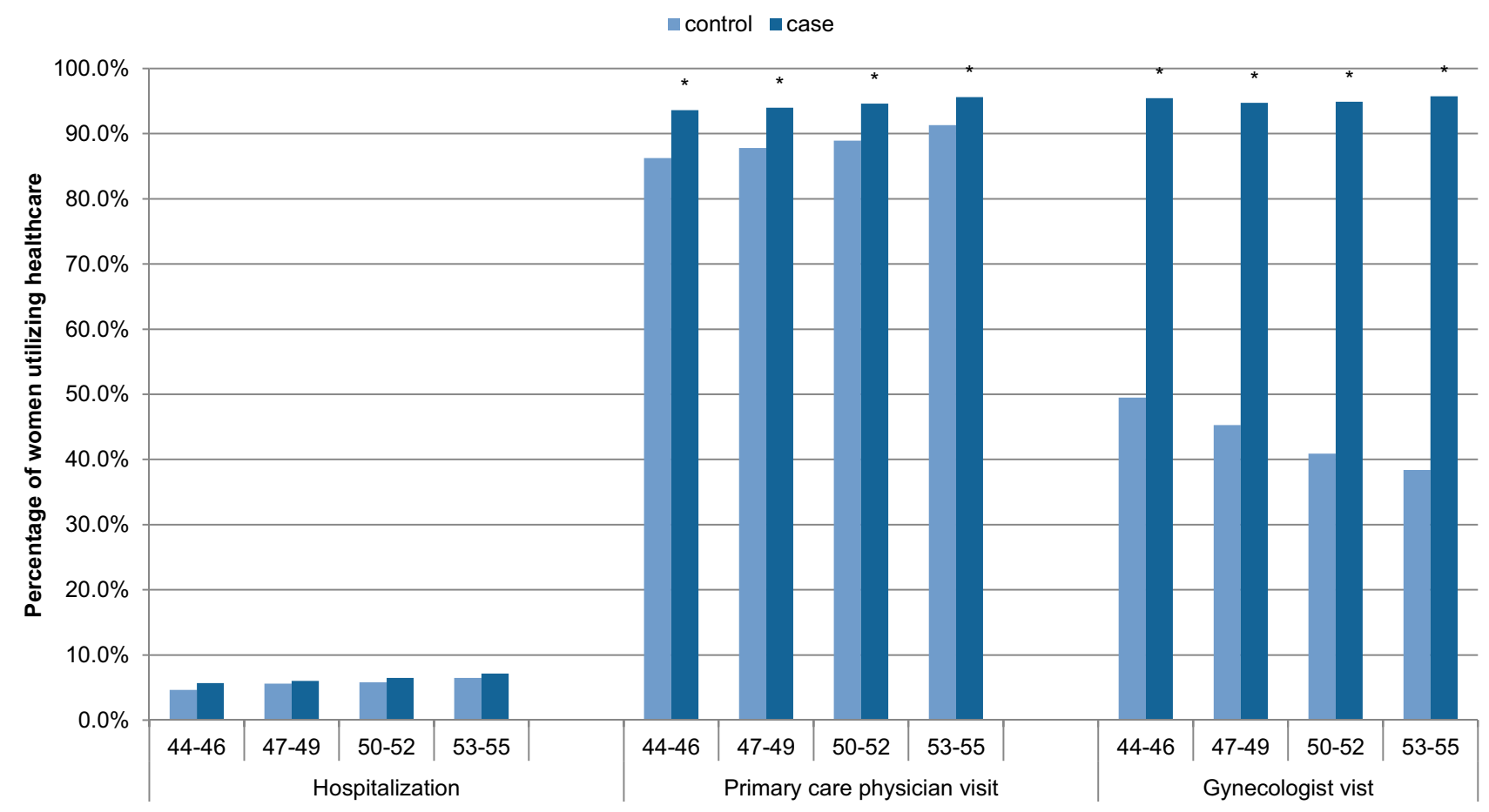

Figure 3 One-year post-index prevalence of healthcare utilization for symptomatic women (cases) versus women in the reference group (controls), N=34,092. *Significant difference between menopause and control cohorts.

The incremental increase in health costs for physician visits and hospitalizations was 574 shekels per woman per year equal to 149 purchasing power parity dollars (Ministry of Health prices, 2015). This annual direct perperson costs of menopausal symptoms are comparable to the one calculated in the US (\$248) that was based on expert clinical opinion regarding 28 medical conditions common to menopausal women. ${ }^{22}$

Symptomatic women had a lower proportion of smokers, diabetes mellitus, hypertension and osteoporosis. This appears to be inconsistent with some published studies that indicate that smoking may be associated with early onset of menopause. ${ }^{23-27}$ However, $2.2 \%$ of the symptomatic women and $3.2 \%$ of women in the reference group had unknown smoking status in their medical notes, which could affect the overall smoking status of the two groups.

In addition we would expect to see a higher proportion of women with osteoporosis among symptomatic women as onset of menopause is associated with the development of osteoporosis due to the decrease in estrogen over this time period. We did not observe this difference at baseline, however we do observe an increase in osteoporosis diagnosis after index date among symptomatic women which

Table 3 Adjusted Odds Ratios Associated with Categorical Healthcare Utilization and Hysterectomy Procedures (Yes/No) in the Index Year (Using Conditional Logistic Regression)

\begin{tabular}{|l|l|l|l|}
\hline & $\begin{array}{l}\text { Reference Group } \\
\text { (Controls) } \mathbf{n = 1 7 , 0 4 6} \\
\mathbf{N}(\%)\end{array}$ & $\begin{array}{l}\text { Symptomatic Women (Cases) } \\
\mathbf{n = 1 7 , 0 4 6} \\
\mathbf{N}(\%)\end{array}$ & $\begin{array}{l}\text { Adjusted OR }^{\mathbf{a}} \\
\mathbf{( 9 5 \%} \mathbf{C I})\end{array}$ \\
\hline $\begin{array}{l}\text { Hospitalizations } \\
\text { PCP visits }\end{array}$ & $960(5.6 \%)$ & $1,070(6.3 \%)$ & $1.102(1.006,1.207)$ \\
Gynecologist visits & $15,075(88.4 \%)$ & $16,086(94.4 \%)$ & $1.901(1.734,2.084)$ \\
Hysterectomy procedures & $7,401(43.4 \%)$ & $16,196(95.0 \%)$ & $24.835(22.357,27.589)$ \\
$(n=31,688)$ & $52(0.3 \%)$ & $121(0.8 \%)$ & $2.262(1.630,3.140)$ \\
\hline
\end{tabular}

Notes: aAdjusted for age at diagnosis, SES, smoking, PCP visits, comorbidities at index: diabetes mellitus, osteoporosis, depression, anxiety, insomnia, drug use within 6 months before index: hypnotics, SSRI, SNRI, bisphosphonates.

Abbreviations: PCP, primary care physician; SES, socioeconomic status; SSRI, selective serotonin reuptake inhibitors; SNRI, serotonin-norepinephrine reuptake inhibitor. 
Table 4 Adjusted Odds Ratios Associated with the Frequency of Hospitalizations, Primary Care Physician Visits and Gynecologist Visits Using for Index Year (Using Generalized Linear Regression Modeling)

\begin{tabular}{|c|c|c|c|c|}
\hline & $\begin{array}{l}\text { Reference Group } \\
\text { (Controls) } \\
\mathrm{n}=\mid 7,046, \\
\text { Mean (SD) }\end{array}$ & $\begin{array}{l}\text { Symptomatic Women } \\
\text { (Cases) } n=\mid 7,046, \\
\text { Mean (SD) }\end{array}$ & $\begin{array}{l}\text { Adjusted } O^{a} \\
(95 \% \mathrm{Cl})\end{array}$ & $\begin{array}{l}\text { Added Number of Visits per Patient } \\
\text { for Index Year }\end{array}$ \\
\hline Hospitalizations & $0.069(0.326)$ & $0.078(0.348)$ & $\begin{array}{l}\text { I.122 (1.033, } \\
1.218)\end{array}$ & $0.01(0,0.020)$ \\
\hline PCP visits & $6.912(6.506)$ & $8.23(6.926)$ & $\begin{array}{l}\text { I.I54 (I.128, } \\
\text { I.I8I) }\end{array}$ & $1.07(0.890,1.25)$ \\
\hline $\begin{array}{l}\text { Gynecologist } \\
\text { visits }\end{array}$ & $0.94 I(1.65)$ & $2.052(2.14)$ & $\begin{array}{l}2.154(2.093 \\
2.216)\end{array}$ & $1.09(1.030,1.14)$ \\
\hline
\end{tabular}

Notes: adjusted for age at diagnosis, SES, smoking, PCP visits, comorbidities at index: diabetes, Osteoporosis, depression, anxiety, insomnia, drug use within 6 months before index: hypnotics, SSRI, SNRI, bisphosphonates.

Abbreviations: PCP, primary care physician; SES, socioeconomic status; SSRI, selective serotonin reuptake inhibitors; SNRI, serotonin-norepinephrine reuptake inhibitor.

may be as a result of increased PCP and gynecology consultations and hence increased osteoporosis testing as a result of those visits. ${ }^{28}$

Symptomatic women had a higher proportion of depression, anxiety and insomnia in the year before and after index date as compared to women in the reference group. Study findings suggest that documented history of depression, anxiety and insomnia and related medication purchases are important predispositions for menopause symptoms or may indicate a lag between symptom initiation and treatment of menopausal symptoms. ${ }^{27}$ These symptoms are typically reported during the late premenopausal years when a decline in estrogen production is expected and before a menopausal diagnosis is given. These symptoms were also more likely to be reported among symptomatic women in the year following index date as typical characteristics of menopause. ${ }^{3}$ Our results show a lower proportion of women who were diagnosed with these conditions among symptomatic women as compared to other studies. ${ }^{2,29}$ Under-reporting of these symptoms may be due to cultural factors which influence symptom perception ${ }^{30,31}$ or due to the perceived "stigma" of suffering from mental illness. ${ }^{32}$ As awareness increases and more women request medical help, the burden on the health system is expected to rise.

Up to $95 \%$ of symptomatic women visited their PCP and gynecologist during the year following index date which is consistent with a study from Australia where $86 \%$ of women reported having consulted physicians for their menopausal symptoms ${ }^{33}$ and as reported in the STRIDE study which found greater healthcare resource use for women experiencing hot flashes. ${ }^{34}$ Our study results are also in line with a previous report demonstrating an increase of 2.8 visits to care providers over a 6-month period. ${ }^{35}$ The high proportion of women visiting physicians in our cohort (reaching 8.4 visits annually among symptomatic women) could be due to the high accessibility of cost-free ambulatory medical services in Israel. ${ }^{36,37}$ However, the number of gynecologists with a sub-specialty in menopause is low and therefore women may not be getting the response they require, and move from physician to physician. The increase in hysterectomy procedures among cases could be connected to increased physician visits, as there is increased likelihood of other findings such as uterine myoma, uterine polyps or prolapse sometimes resulting in hysterectomy. In addition, older age is a risk factor for uterine atypical hyperplasia of carcinoma, also treated by hysterectomy.

Other studies also report an increase in healthcare utilization including hospitalization and emergency room services $^{16,38}$ and the direct costs of care are similar or greater than a number of other medical conditions such as esophageal disorders and osteoporosis. ${ }^{22}$

Awareness of menopause and attitudes towards it can influence the degree of symptoms. Women who had a negative attitude suffered more from depression or sleeping disorders than those with a positive one. ${ }^{39}$ In addition, lack of knowledge of the natural process of menopause and lifestyle interventions are a major challenge to symptom control. ${ }^{40}$ Management strategies should include empowering women to participate in their care that will improve their sense of control and overall care, ${ }^{41,42}$ together with exercise and diet recommendations, including isoflavones, calcium and vitamin D which may have favorable effects on menopausal symptoms and quality of life ${ }^{43}$ and sexual health. ${ }^{44}$ 
The gold standard treatment for women that seek control of their symptoms is hormone replacement therapy (HRT), but the optimal course of treatment is unclear due to mixed results from studies. ${ }^{45,46}$ Initial interpretation of the Women's Health Initiative in the early 2000s saw a rapid decrease in HRT use, though current thinking appears to show that women under the age of 60 at the onset of menopause have a favorable risk-benefit profile when taking HRT for short-term relief of vasomotor symptoms. ${ }^{47,48}$

Alternative treatments include black cohosh or isoflavones, however the evidence for their benefit and safety from randomized-controlled trials is poor. ${ }^{49,50}$

This study is a large population based sample, with longitudinal data allowing collection of real-world data and analysis of a wide range of symptoms. However, it may have limitations associated with its retrospective cohort design. Data on purchases made outside of MHS pharmacies were not captured; however, patients are unlikely to buy medications outside of MHS due to their discounted price within MHS. It should also be noted that actual medication use is unknown, as dispensed medications may not be consumed. However, previous studies have demonstrated the validity of this approach for measuring compliance with chronic medications. ${ }^{51}$

\section{Conclusion}

Menopausal symptoms are associated with increased burden of disease and healthcare utilization, including hospitalizations, physician visits, gynecologist visits and greater likelihood of undergoing hysterectomy. This burden is expected to rise further as awareness and social acceptance of peri- and post-menopausal symptoms increase. Better education on menopause for physicians and effective communication between healthcare providers and patients can help to better manage menopausal symptoms. There is an urgent need for doctors who specialize in menopause in order to help reduce the burden of unnecessary physician visits.

\section{Synopsis}

Medically documented menopausal symptoms are associated with increased burden of disease and healthcare utilization and greater likelihood of undergoing hysterectomy within one year of diagnosis.

\section{Ethics Approval}

This study was reviewed and approved by the Institutional Review Board of the Assuta Medical Center in Israel, 5th November 2017. All data were anonymized.

\section{Acknowledgments}

This study was presented as a poster at the ISPOR (International Society for Pharmacoeconomics and Outcomes Research) European conference, November 2019, Copenhagen Denmark.

\section{Author Contributions}

SSM - design, planning, conduct, data analysis, manuscript writing. GC - design, planning, data analysis, manuscript writing. SB - data analysis, manuscript writing. VS - design, planning, data analysis, manuscript writing. All authors contributed to data analysis, drafting or revising the article, gave final approval of the version to be published, and agree to be accountable for all aspects of the work.

\section{Funding}

This work was supported by Pfizer, Israel.

\section{Disclosure}

The authors declare that they have no conflicts of interest in this work.

\section{References}

1. Umland EM. Treatment strategies for reducing the burden of menopause-associated vasomotor symptoms. J Manag Care Pharm. 2008;14(3 Supp A):14-19. doi:10.18553/jmcp.2008.14.S3-A.14

2. Kleinman NL, Rohrbacker NJ, Bushmakin AG, Whiteley J, Lynch WD, Shah SN. Direct and indirect costs of women diagnosed with menopause symptoms. J Occup Environ Med. 2013;55 (4):465-470. doi:10.1097/JOM.0b013e3182820515

3. Freeman EW, Sammel MD, Lin H, Nelson DB. Associations of hormones and menopausal status with depressed mood in women with no history of depression. Arch Gen Psychiatry. 2006;63(4):375-382. doi:10.1001/archpsyc.63.4.375

4. Joffe H, Hall JE, Soares CN, et al. Vasomotor symptoms are associated with depression in perimenopausal women seeking primary care. Menopause. 2002;9(6):392-398. doi:10.1097/00042192-200211000-00003

5. Williams RE, Kalilani L, DiBenedetti DB, Zhou X, Fehnel SE, Clark RV. Healthcare seeking and treatment for menopausal symptoms in the United States. Maturitas. 2007;58(4):348-358. doi:10.1016/j. maturitas.2007.09.006

6. Berecki-Gisolf J, Begum N, Dobson AJ. Symptoms reported by women in midlife: menopausal transition or aging? Menopause. 2009;16(5):1021-1029. doi:10.1097/gme.0b013e3181a8c49f

7. Keenan NL, Mark S, Fugh-Berman A, Browne D, Kaczmarczyk J, Hunter C. Severity of menopausal symptoms and use of both conventional and complementary/alternative therapies. Menopause. 2003;10 (6):507-515. doi:10.1097/01.GME.0000064865.58809.3E 
8. Reed SD, Ludman EJ, Newton KM, et al. Depressive symptoms and menopausal burden in the midlife. Maturitas. 2009;62(3):306-310. doi:10.1016/j.maturitas.2009.01.002

9. Freeman EW, Sherif K. Prevalence of hot flushes and night sweats around the world: a systematic review. Climacteric. 2007;10 (3):197-214. doi:10.1080/13697130601181486

10. Monteleone P, Mascagni G, Giannini A, Genazzani AR, Simoncini T. Symptoms of menopause - global prevalence, physiology and implications. Nat Rev Endocrinol. 2018;14(4):199-215. doi:10.10 38/nrendo. 2017.180

11. Schoenaker DA, Jackson CA, Rowlands JV, Mishra GD. Socioeconomic position, lifestyle factors and age at natural menopause: a systematic review and meta-analyses of studies across six continents. Int J Epidemiol. 2014;43(5):1542-1562. doi:10.1093/ije/ dyu094

12. Avis NE, Colvin A, Bromberger JT, et al. Change in health-related quality of life over the menopausal transition in a multiethnic cohort of middle-aged women: study of women's health across the nation. Menopause (New York, NY). 2009;16(5):860-869. doi:10.1097/ gme.0b013e3181a3cdaf

13. Williams RE, Levine KB, Kalilani L, Lewis J, Clark RV. Menopausespecific questionnaire assessment in US population-based study shows negative impact on health-related quality of life. Maturitas. 2009;62(2):153-159. doi:10.1016/j.maturitas.2008.12.006

14. Kjerulff KH, Frick KD, Rhoades JA, Hollenbeak CS. The cost of being a woman: a national study of health care utilization and expenditures for female-specific conditions. Womens Health Issues. 2007;17(1):13-21. doi:10.1016/j.whi.2006.11.004

15. Sarrel P, Portman D, Lefebvre P, et al. Incremental direct and indirect costs of untreated vasomotor symptoms. Menopause. 2015;22 (3):260-266. doi:10.1097/GME.0000000000000320

16. Whiteley J, DiBonaventura M, Wagner J-S, Alvir J, Shah S. The impact of menopausal symptoms on quality of life, productivity, and economic outcomes. J Womens Health. 2013;22(11):983-990. doi:10.1089/jwh.2012.3719

17. Israel Central Bureau of Statistics. Characterization and Classification of Geographic Units by the Soci-Economic Level of the Population 2008. Jerusalem, Israel; 2013. Publication No. 1530.

18. Shalev V, Chodick G, Goren I, Silber H, Kokia E, Heymann AD. The use of an automated patient registry to manage and monitor cardiovascular conditions and related outcomes in a large health organization. Int $J$ Cardiol. 2011;152(3):345-349. doi:10.1016/j. ijcard.2010.08.002

19. Goldshtein I, Chandler J, Shalev V, et al. Osteoporosis in the community: findings from a novel computerized registry in a large health organization in Israel. Aging Res Clin Pract. 2015;4(1):59-65.

20. Chodick G, Heymann AD, Shalev V, Kookia E. The epidemiology of diabetes in a large Israeli HMO. Eur $J$ Epidemiol. 2003;18 (12):1143-1146. doi:10.1023/B:EJEP.0000006635.36802.c8

21. Deyo RA, Cherkin DC, Ciol MA. Adapting a clinical comorbidity index for use with ICD-9-CM administrative databases. $J$ Clin Epidemiol. 1992;45(6):613-619. doi:10.1016/0895-4356 (92)90133-8

22. Assaf AR, Bushmakin AG, Joyce N, Louie MJ, Flores M, Moffatt M. The relative burden of menopausal and postmenopausal symptoms versus other major conditions: a retrospective analysis of the medical expenditure panel survey data. Am Health Drug Benefits. 2017;10 (6):311-321.

23. Whitcomb BW, Purdue-Smithe AC, Szegda KL, et al. Cigarette smoking and risk of early natural menopause. Am J Epidemiol. 2018;187(4):696-704. doi:10.1093/aje/kwx292

24. Hayatbakhsh MR, Clavarino A, Williams GM, Sina M, Najman JM. Cigarette smoking and age of menopause: a large prospective study. Maturitas. 2012;72(4):346-352. doi:10.1016/j.maturitas.2012.05.004
25. Sun L, Tan L, Yang F, et al. Meta-analysis suggests that smoking is associated with an increased risk of early natural menopause. Menopause. 2012;19(2):126-132. doi:10.1097/gme.0b013e318224f9ac

26. Mishra GD, Chung H-F, Cano A, et al. EMAS position statement: predictors of premature and early natural menopause. Maturitas. 2019;123:82-88. doi:10.1016/j.maturitas.2019.03.008

27. Harlow BL, Signorello LB. Factors associated with early menopause. Maturitas. 2000;35(1):3-9. doi:10.1016/S0378-5122(00)00092-X

28. Ohta H, Sugimoto I, Masuda A, et al. Decreased bone mineral density associated with early menopause progresses for at least ten years: cross-sectional comparisons between early and normal menopausal women. Bone. 1996;18(3):227-231. doi:10.1016/8756-3282(95)00480-7

29. Woods NF, Mitchell ES. Symptoms during the perimenopause: prevalence, severity, trajectory, and significance in women's lives. Am $J$ Med. 2005;118(12):14-24. doi:10.1016/j.amjmed.2005.09.031

30. Melby MK, Lock M, Kaufert P. Culture and symptom reporting at menopause. Hum Reprod Update. 2005;11(5):495-512. doi:10.1093/ humupd/dmi018

31. Kaufert P, Syrotuik J. Symptom reporting at the menopause. Soc Sci Med E. 1981;15(3):173-184.

32. Tal A, Roe D, Corrigan PW. Mental illness stigma in the Israeli context: deliberations and suggestions. Int $J$ Soc Psychiatry. 2007;53(6):547-563. doi:10.1177/0020764007082346

33. Guthrie J, Dennerstein L, Taffe J, Donnelly V. Health care-seeking for menopausal problems. Climacteric. 2003;6(2):112-117. doi:10.10 80/cmt.6.2.112.117

34. Hess R, Chang C, Ness R, Hays R, Kapoor W, Bryce C, editors. The associations of menopause and health-related quality of life with health services utilization: results from the STRIDE study. Abstract presented at the 32nd Annual Meeting of the Society of Medical Decision Making; 2010; Toronto, Ontario, Canada.

35. Xu J, Bartoces M, Neale AV, Dailey RK, Northrup J, Schwartz KL. Natural history of menopause symptoms in primary care patients: a MetroNet study. J Am Board Fam Med. 2005;18(5):374-382. doi:10.3122/jabfm.18.5.374

36. Antonovsky A. A model to explain visits to the doctor: with specific reference to the case of Israel. J Health Soc Behav. 1972;13 (4):446-454. doi: $10.2307 / 2136838$

37. Baron-Epel O, Garty N, Green MS. Inequalities in use of health services among Jews and Arabs in Israel. Health Serv Res. 2007;42 (3p1):1008-1019. doi:10.1111/j.1475-6773.2006.00645.x

38. Shyu Y-K, Pan C-H, Liu W-M, Hsueh J-Y, Hsu C-S, Tsai P-S. Healthrelated quality of life and healthcare resource utilization in Taiwanese women with menopausal symptoms: a nation-wide survey. J Nurs Res. 2012;20(3):208-218. doi:10.1097/jnr.0b013e318265619b

39. Bloch A. Self-awareness during the menopause. Maturitas. 2002;41 (1):61-68. doi:10.1016/S0378-5122(01)00252-3

40. Yazdkhasti M, Simbar M, Abdi F. Empowerment and coping strategies in menopause women: a review. Iran Red Crescent Med J. 2015;17(3). doi:10.5812/ircmj.18944

41. Hall L, Callister LC, Berry JA, Matsumura G. Meanings of menopause: cultural influences on perception and management of menopause. J Holist Nurs. 2007;25(2):106-118. doi:10.1177/0898010107299432

42. Hickey M, Szabo RA, Hunter MS. Non-hormonal treatments for menopausal symptoms. BMJ. 2017;359:j5101. doi:10.1136/bmj.j5101

43. Vitale SG, Caruso S, Rapisarda AMC, Cianci S, Cianci A. Isoflavones, calcium, vitamin D and inulin improve quality of life, sexual function, body composition and metabolic parameters in menopausal women: result from a prospective, randomized, placebo-controlled, parallel-group study. Prz Menopauzalny Menopause Rev. 2018;17(1):32. doi:10.5114/pm.2018.73791

44. Lagana AS, Vitale SG, Stojanovska L, et al. Preliminary results of a single-arm pilot study to assess the safety and efficacy of visnadine, prenylflavonoids and bovine colostrum in postmenopausal sexually active women affected by vulvovaginal atrophy. Maturitas. 2018;109:78-80. doi:10.1016/j.maturitas.2017.12.015 
45. Heiss G, Wallace R, Anderson GL, et al. Health risks and benefits 3 years after stopping randomized treatment with estrogen and progestin. JAMA. 2008;299(9):1036-1045. doi:10.1001/jama.299.9. 1036

46. Collaborators MWS. Breast cancer and hormone-replacement therapy in the million women study. Lancet. 2003;362(9382):419-427.

47. Lobo RA. Hormone-replacement therapy: current thinking. Nat Rev Endocrinol. 2017;13(4):220. doi:10.1038/nrendo.2016.164

48. NICE. UK. [updated January 22, 2019]. Available from: https://www. nice.org.uk/guidance/ng23. Accessed May 13, 2020.
49. Rees M. Alternative treatments for the menopause. Best Pract Res Clin Obstet Gynaecol. 2009;23(1):151-161. doi:10.1016/j.bpobgyn. 2008.10.006

50. Moore TR, Franks RB, Fox C. Review of efficacy of complementary and alternative medicine treatments for menopausal symptoms. J Midwifery Womens Health. 2017;62(3):286-297. doi:10.1111/jmwh.12628

51. Steiner JF, Koepsell TD, Fihn SD, Inui TS. A general method of compliance assessment using centralized pharmacy records. Description and validation. Med Care. 1988;26(8):814-823. doi:10. 1097/00005650-198808000-00007

\section{Publish your work in this journal}

The International Journal of Women's Health is an international, peerreviewed open-access journal publishing original research, reports, editorials, reviews and commentaries on all aspects of women's healthcare including gynecology, obstetrics, and breast cancer. The manuscript management system is completely online and includes a very quick and fair peer-review system, which is all easy to use. Visit http://www.dovepress.com/testimonials.php to read real quotes from published authors. 